\title{
Preconceito e intenção em manter contato social: evidências acerca dos valores humanos
}

\author{
Tatiana Cristina Vasconcelos ${ }^{1}$ \\ Valdiney Veloso Gowveia \\ Marcílio Lira de Souza Filho \\ Deliane Macedo Farias de Sousa \\ Girlene Ribeiro de Jesus
}

\begin{abstract}
Resumo
Este trabalho objetivou conhecer como os valores humanos estão relacionados às atitudes preconceituosas e à intenção em manter o contato social com pessoas negras. Para tanto, contou-se com uma amostra de 303 pessoas da população geral da cidade de João Pessoa (PB), a maioria mulheres com idades compreendidas entre 12 e 74 anos $(\mathrm{M}=30,5 ; \mathrm{DP}=14,2)$. Seguindo-se um procedimento padrão, foi pedido que respondessem aos seguintes instrumentos: Escala de Atitudes Preconceituosas, Escala de Intenção de Contato Social, Questionário dos Valores Humanos Básicos e um questionário de Caracterização da Amostra. Os resultados foram consistentes em relação a achados anteriores. As atitudes preconceituosas correlacionaram-se principalmente com os valores suprapessoais. Encontrouse, ademais, que os valores suprapessoais e de realização atuaram como bons preditores para as atitudes preconceituosas, e que estas foram boas explicadoras da intenção em manter contato social com negros.
\end{abstract}

Palavras-Chave: Negros; Atitudes preconceituosas; Contato social; Valores.

\section{Prejudice and intention to maintain social contact: Evidences concerning human values}

\begin{abstract}
The current research aimed to know how the human values is related to the prejudiced attitudes and to the intention to maintain social contact with Blacks. 303 subjects from the general population of João Pessoa (PB) were considered. The respondents were mainly women, and the ages varying from 12 to 74 years $(\mathrm{M}=30,5 ; \mathrm{DP}=14,2)$. The Prejudiced Attitudes Scale, Intention to Maintain Social Contact Scale, Basic Human Values Questionnaire and demographics questions were applied. Results showed that the prejudiced attitudes were primarily correlated with the suprapersonal values. Furthermore, the suprapersonals and of achievement values were good predictors, and satisfactory to explain the intention in maintaining social contact with Blacks.

Keywords: Blacks; Prejudiced attitudes; Social contact; Values.
\end{abstract}

Apesar do preconceito racial ser legalmente proibido em diversos países, parece seguir presente nas práticas sociais diárias. O preconceito, além de ser um construto de interesse da Psicologia Social, apresenta-se como um tema de suma importância para se entender a dinâmica das relações intergrupais. Vários estudos têm sido desenvolvidos com a finalidade de entendê-lo, bem como conhecer suas variáveis correlatas (ver, por exemplo, Cover, 1995; Gómez \& Huici, 2001; Plant \& Devine, 1998; Pozo, Armas \& Peres, 2000; Vera \& Martínez, 1994). A seguir, serão tecidas algumas considerações teóricas a respeito do preconceito e suas manifestações comportamentais, bem como das relações conhecidas entre o preconceito e os valores humanos.

No intuito de apresentar uma definição para o termo preconceito, observou-se que este é utilizado por vários autores de diversas formas, de modo que tentar apresentar uma lista de definições formuladas e reformuladas ao longo do tempo seria uma tarefa quase inesgotável (Costa, 2001). Por mais que se tente relacionar, juntar e combinar os vários aspectos para definir o preconceito, corre-se o risco de não conseguir captar todos os sentidos que os indivíduos empregam ao construto, uma vez que suas definições diferem amplamente na intensidade e no modo de expressão. Atualmente, por exemplo, fala-se em preconceito simbólico, sutil, moderno ou aversivo (Biernat, Vescio, Theno, \& Crandall, 1996; Gómez \& Huici, 2001; Navas, 1998; Pettigrew \& Meertens, 1995), uma forma um pouco diversa, mais branda ou moderna, do preconceito aberto ou flagrante estudado no período posterior à Segunda Grande Guerra (Alport, 1954). Todas, porém, têm algo em comum: envolvem um sentimento negativo dirigido a um grupo particular de pessoas (Brown, 1995), o que potencializaria na pessoa preconceituosa uma maior tendência a intencionar o distanciamento ou efetivamente evitar o contato social com os representantes de tais grupos. Não obstante, o termo preconceito vem sendo referido como a adoção de um posicionamento ou atitude negativa direcionada a algumas pessoas pelo fato

\footnotetext{
${ }^{1}$ Endereço para correspondência:

E-mail: vasconcelostc@yahoo.com.br
} 
de pertencerem ou assemelharem-se a um grupo que esteja dotado de determinados aspectos específicos, que são percebidos como negativos (ver, por exemplo, Brown, 1995 \& Jones, 1973).

Em relação ao estudo do preconceito direcionado aos negros, observa-se que tradicionalmente este tem como foco as análises de sua relação com certas estruturas cognitivas. Neste contexto, os estereótipos têm sido o tema a que se tem dedicado a maior parte dos estudos (Rodrígues-Bailón, Barranco \& Casado, 2000). Sem dúvida, isto é importante; entretanto, as cognições acerca dos grupos não se baseiam exclusivamente nos estereótipos. Assim, diversos autores têm chamado a atenção para a importância dos valores e das normas como construtos que podem contribuir para modelar e modificar as atitudes intergrupais. Desse modo, a partir dos anos 70, surgem vários modelos que enfatizam a relevância dos valores, sua estrutura e hierarquia na compreensão do preconceito (Biernat, Vescio, Theno \& Crandall, 1996) e de outras atitudes (Homer \& Kahle, 1988). Não obstante, especificamente no Brasil, poucos estudos têm considerado a importância dos valores ao analisar as atitudes preconceituosas.

Schwartz e Bilsky (1987) afirmam que os valores guiam a seleção e avaliação dos comportamentos e das situações, bem como estão hierarquizados de acordo com sua importância relativa e constituem elementos cruciais dentro de uma cultura; portanto, são um ponto central na compreensão das relações que se estabelecem entre os grupos. Assim, pode-se dizer que os valores têm uma relação estreita com o preconceito e sua manifestação, o que justifica os muitos estudos que estão sendo desenvolvidos neste sentido.

Como exemplo de tais estudos, pode-se citar o trabalho de Gómez e Huici (2001), que apresentam uma extensa revisão bibliográfica a respeito da relação entre valores e preconceito, apontando que os estudos realizados a respeito dividem-se em três grandes enfoques: 1) teorias do novo racismo, que têm como eixo os valores associados às atitudes em relação às minorias étnicas, especificamente em relação aos negros, nas quais se associa a avaliação a estes grupos com a percepção de que os membros da minoria violam certos valores de grande importância para os membros da maioria; 2) enfoques que põem ênfase na congruência de crenças ao tratar das relações intergrupais, como é o caso de Rokeach (1973) e 3) enfoques que correspondem à perspectiva de Struch e Schwartz (1989), em que a ênfase é dada à diferença na hierarquia de valores dos membros que compõem os exogrupos.

Vera e Martínez (1994), considerando uma amostra de universitários espanhóis, buscaram conhecer em que medida os tipos motivacionais de valores do modelo de Schwartz poderiam explicar o nível de preconceito generalizado em direção a membros de grupos minoritários (por exemplo, ciganos e sulamericanos). Dividindo os sujeitos em dois grupos (de alto e baixo preconceito), observaram que o universalismo e a tradição foram os valores preponderantes no momento de classificá-los. Especificamente, os mais preconceituosos deram menos importância ao primeiro e mais ao segundo tipo motivacional.

Resultados bastante similares aos apresentados acima foram relatados por Gómez e Huici (2001). Estes, contando com uma amostra de colegiais pré-universitários, subdivididos em dois grupos, segundo a imagem que tinham do exogrupo (positiva vs. negativa), comprovaram que aqueles com uma imagem positiva do exogrupo pontuaram mais no tipo motivacional universalismo, como se poderia esperar do modelo de Schwartz (1994); contudo, contrário ao esperado, também o fizeram em tradição.

Com a finalidade de conhecer que tipos de valores poderiam estar relacionados com a prontidão para o contato social com exogrupos, Sagiv e Schwartz (1995) realizaram um estudo com grupos de judeus, árabes cristãos e muçulmanos, verificando que, de maneira geral, a prontidão para o contato social correlacionouse, de maneira positiva, com os valores universalismo e autodireção, e de maneira negativa, com os valores tradição, segurança e conformidade. Assinalam ainda que a influência dos valores sobre a prontidão para o contato com exogrupos depende do fato do indivíduo ser um membro de um grupo dominante ou minoritário.

Como vem sendo visto, uma boa quantidade de pesquisas vem tratando as variáveis preconceito e valores com base na tipologia de Schwartz (1994). No presente estudo, particularmente, optou-se por adotar uma tipologia alternativa. Trata-se da Tipologia dos Valores Humanos Básicos (Gouveia, 1998). Tal tipologia tem sido apresentada como uma boa alternativa e tem sido útil para compreender os mais variados aspectos da vida social, como por exemplo: as atitudes ambientais (Coelho, Gouveia, Milfont, Meira \& Schultz, 2000); a intenção em constituir família (Milfont, 2001); o uso potencial de drogas (Coelho Júnior, 2001); os comportamentos delitivos (Formiga, 2002); a identidade social (Gouveia, Albuquerque, Clemente \& Espinosa, 2002); o bem-estar subjetivo (Chaves, 2003); aspectos diretamente envolvidos com o preconceito, como por exemplo, a motivação para responder não preconceituosamente (Gouveia, Souza Filho, Chaves, Rivera \& Queiroga, 2003); entre outros.

De acordo com a perspectiva supracitada, os valores são entendidos como categorias desejáveis que assumem um caráter orientador das condutas. Essas categorias teriam origem nas necessidades humanas ou ainda nas pré-condições para satisfazê-las. Em outras palavras, poder-se-ia dizer que os valores seriam representações cognitivas das necessidades (para maiores 
detalhes, ver Gouveia, 1998). De acordo com essa teoria dos valores humanos, para identificar cada valor básico deve-se tomar como referência a teoria das necessidades de Maslow (1954, 1970), cujos principais fundamentos são os seguintes: as necessidades humanas são relativamente universais, são neutras ou positivas, obedecem a uma hierarquia, o homem caminha em direção à autorealização, e a pessoa é um todo integrado e organizado.

Em função da teoria maslowiana das necessidades, foram identificadas seis funções psicossociais representadas por um conjunto de valores específicos, totalizando 24 valores básicos. As funções psicossociais agrupam-se em pares, compondo assim, três critérios valorativos de orientação. A seguir são descritos os critérios de orientação com suas respectivas funções psicossociais, cada uma acompanhada, entre parênteses, de seus valores básicos definidores.

Inicialmente, no critério de orientação pessoal, dá-se ênfase ao próprio indivíduo, ao proporcionamento de satisfação física ou de tornar-se alguém importante ou influente. Estão aqui englobadas as funções psicossociais de experimentação (estimulação, emoção, prazer e sexual) e de realização (êxito, poder, prestígio, autodireção e privacidade). Por sua vez, no critério de orientação central, que é compatível com os demais critérios, enfatiza-se tanto o indivíduo destacado do contexto quanto a necessidade de, uma vez existindo, dar importância a uma conjuntura social justa, onde todos possam desenvolver-se integralmente. Abrange as funções dos valores de existência (estabilidade pessoal, saúde e sobrevivência) e suprapessoais (beleza, conhecimento, justiça social e maturidade). Finalmente, no critério de orientação social, dá-se ênfase às questões sociais, à manutenção das normas já constituídas e às relações interpessoais amistosas. Encontram-se aqui, as funções psicossociais dos valores normativos (religiosidade, ordem social, tradição e obediência); e interacionais (afetividade, apoio social, afiliação e honestidade).

Como assinalado antes, essa tipologia vem sendo utilizada em diversos estudos recentes no Brasil e, além disso, sua medida apresenta parâmetros psicométricos satisfatórios (Gouveia, 1998). Portanto, considera-se plausível sua utilização neste estudo.

Em relação ao que se comentou até o momento, o presente trabalho teve como objetivo principal buscar conhecer o papel que os valores humanos assumem na compreensão das atitudes preconceituosas. Secundariamente, buscou-se analisar o poder explicativo que os valores têm sobre as atitudes preconceituosas e o poder explicativo que estas têm sobre a intenção em manter o contato social com negros. Os procedimentos metodológicos seguidos para consecução destes objetivos serão descritos no tópico a seguir.

\section{Método}

\section{Participantes}

Para lograr os objetivos do presente estudo, participaram 303 pessoas provenientes da população geral, residentes na cidade de João Pessoa, sendo a maioria do sexo feminino (63\%), com idades compreendidas entre 12 e 74 anos $(M=30,5$; DP = 14,2). Dos respondentes, $42,7 \%$ afirmaram ter completado ou estar cursando o nível médio de escolaridade.

\section{Instrumentos}

Para a coleta das informações, os participantes responderam a um questionário composto por quatro instrumentos, descritos a seguir:

Escala de Atitudes Preconceituosas. Elaborada por Stephan, Ybarra, Martínez, Schwarzwald e Tur-Kaspa (1998), está composta por dez itens indicadores de atitudes frente aos negros, sendo cinco positivas (admiração, aceitação, afeto, simpatia e cordialidade) e cinco negativas (hostilidade, desagrado, indiferença, ódio e rejeição), respondidos numa escala de cinco pontos, variando de $1=$ Nunca a $5=$ Sempre, na qual o respondente expressa a freqüência com que apresenta cada atitude. No Brasil, de acordo com os dados desta pesquisa, verificou-se a adequabilidade da escala em questão, tendo a mesma apresentado um fator geral, com um coeficiente de consistência interna de 0,81.

Escala de Intenção de Contato Social. Utilizada por Martínez \& Vera (1994) na Espanha. Apresentou naquele contexto parâmetros psicométricos considerados estatisticamente satisfatórios $(\boldsymbol{\alpha}=0,91)$. Está composta de 18 itens que expressam as formas intima e superficial do contato social (por exemplo, Teria amigos negros, No meu negócio não contrataria pessoas negras), respondidos numa escala do tipo Likert, que varia de $1=$ Discordo Totalmente a $5=$ Concordo Totalmente. Nesta pesquisa foram observados parâmetros psicométricos satisfatórios, com uma configuração bifatorial, onde as duas dimensões acima referidas apresentaram adequados índices de consistência interna, sendo 0,82 para o contato íntimo e 0,91 para o contato superficial. A solução composta por um fator, também se mostrou satisfatória, apresentando um alfa de 0,91, igualmente ao que foi encontrado na Espanha.

Questionário dos Valores Básicos. Este instrumento, elaborado e validado por Gouveia (1998), está composto por 24 itens ou valores específicos, seguidos por exemplos de situações (por exemplo, Exxito: obter o que se propõe, ser eficiente em tudo o que faz; Saúde: se preocupar com sua saúde antes de ficar doente, não estar enfermo), respondidos em uma escala com nove pontos. Inicialmente, pede-se ao respondente que leia 
atentamente e indique em uma escala de 7 pontos, com os extremos $1=$ Nada importante e $7=$ Muito importante, o grau de importância de cada um dos valores; uma vez respondidos, o participante terá que reconsiderar a lista com todos os valores e indicar aquele que considere o mais importante e o menos importante de todos. Para estes dois valores serão atribuídos os escores 8 e 0 , respectivamente. Informações acerca de suas qualidades psicométricas podem ser confirmadas em Maia (2000).

Caracterização da amostra. Com a finalidade de caracterizar os participantes do estudo, foi elaborada uma página com perguntas de caráter sociodemográfico, como idade, sexo, renda, por exemplo.

\section{Procedimento}

Para a coleta dos dados foram escolhidos bairros na cidade de João Pessoa tidos como pertencentes a diferentes classes sociais. Considerando isso, foi realizado um mapeamento em função da renda, na tentativa de contemplar os diversos níveis econômicos, de modo a otimizar a representatividade do estudo. A aplicação dos instrumentos foi realizada individualmente por colaboradores de ambos os sexos, os quais foram devidamente instruídos a fim de minimizar os efeitos de variáveis externas no momento da aplicação e intervir o mínimo possível nesse processo. Foi adotado o procedimento de contrabalanceamento dos instrumentos, mas deixando a folha de caracterização da amostra sempre como a última parte. Os respondentes foram visitados em suas casas e foram informados de que se tratava de um estudo realizado pela Universidade Federal da Paraíba. Em seguida, acrescentavam-se informações que se restringiam apenas à maneira como deveriam responder ao questionário e ao caráter sigiloso com que seriam encaradas as respostas dadas. Todos os participantes responderam ao questionário individualmente, sendo 25 minutos o tempo médio necessário para o completo preenchimento do mesmo.

\section{Análise dos dados}

Foi utilizada a versão 10.0 do pacote estatístico
SPSSWIN para tabulação e análise dos dados, bem como o programa CORRS, utilizado para comparar coeficientes de correlação. Além das estatísticas descritivas (tendência central e dispersão), também foram efetuadas correlações entre os valores humanos e a pontuação total de atitudes. Ademais, foram executadas análises de regressão, adotando o método stepwise: a primeira com as variáveis valores humanos (variável antecedente) e atitudes preconceituosas (variável conseqüente); a segunda, com as atitudes preconceituosas (variável antecedente) e a intenção para manter o contato social (variável dependente).

\section{Resultados}

A fim de realizar a correlação dos valores humanos com as atitudes preconceituosas e os tipos de intenção em manter o contato social (íntimo vs. superficial), foram efetuados os somatórios dos itens de cada escala com a finalidade de obter uma pontuação total. $\mathrm{Na}$ escala de atitudes preconceituosas, alguns dos itens foram invertidos (por exemplo, admiração e simpatia) e depois somados, de tal forma que o resultado final do somatório expressa diretamente o preconceito. Com a escala de intenção em manter o contato social também foram realizados somatórios, desta vez obedecendo à bifatorialidade da escala, de modo que resultaram dois escores (um para cada tipo de contato) que expressam diretamente a intenção em manter o contato social. No caso dos valores humanos, cada valor básico foi considerado individualmente; não obstante, o escore dos critérios de orientação e das funções psicossociais foi calculado a partir do somatório de seus valores constituintes, realizando sempre uma ponderação, dada a quantidade variável de valores humanos em cada critério ou função. Finalmente, no intuito de controlar o efeito de pontuações extremadas na variável valores humanos, as correlações foram parcializadas pelo somatório de todos os valores humanos básicos. Os resultados destas correlações podem ser visualizados na Tabela 1, a seguir. 
Tabela 1 - Correlação dos valores humanos com as atitudes preconceituosas e a intenção em manter o contato social com negros

\begin{tabular}{|c|c|c|c|c|}
\hline \multirow[t]{2}{*}{ VALORES } & \multirow[t]{2}{*}{$\begin{array}{c}\text { ATITUDES } \\
\text { PRECONCEITUOSAS }\end{array}$} & \multicolumn{3}{|c|}{$\begin{array}{c}\text { INTENÇÃO EM } \\
\text { MANTER O CONTATO }\end{array}$} \\
\hline & & Superficial & Íntimo & Contraste (z) \\
\hline PESSOAIS & $0,27^{* * *}$ & $-0,12$ & $-0,19^{* *}$ & $-1,24$ \\
\hline Experimentação & 0,07 & 0,03 & $-0,03$ & 0,00 \\
\hline Emoção & 0,00 & $-0,01$ & $-0,02$ & $-1,77^{*}$ \\
\hline Estimulação & 0,05 & 0,12 & 0,07 & 0,87 \\
\hline Prazer & 0,05 & $-0,04$ & $-0,05$ & 0,17 \\
\hline Sexual & 0,06 & 0,01 & $-0,05$ & $-0,69$ \\
\hline Realização & $0,33^{* * *}$ & $-0,23^{* * *}$ & $-0,26^{* * *}$ & $-0,55$ \\
\hline Autodireção & 0,07 & 0,08 & 0,13 & $-0,88$ \\
\hline Exxito & 0,09 & 0,00 & $-0,16^{*}$ & 1,39 \\
\hline Poder & $0,27^{* * *}$ & $-0,24^{* * *}$ & $-0,22^{* *}$ & 0,37 \\
\hline Prestígio & 0,13 & $-0,17^{*}$ & $-0,19^{* *}$ & $-0,36$ \\
\hline Privacidade & 0,12 & $-0,10$ & $-0,08$ & 0,35 \\
\hline CENTRAIS & $-0,28^{* * *}$ & $0,27^{* * *}$ & $0,15^{* *}$ & $2,18^{* *}$ \\
\hline Existenciais & $-0,10$ & 0,11 & 0,01 & $1,74^{*}$ \\
\hline Estabilidade Pessoal & $-0,07$ & $0,17^{* *}$ & $-0,05$ & $1,57^{*}$ \\
\hline Saúde & $-0,07$ & 0,04 & 0,07 & $-0,17$ \\
\hline Sobrevivência & $-0,05$ & $-0,00$ & 0,01 & 0,00 \\
\hline Suprapessoais & $-0,27^{* * *}$ & $0,26^{* * *}$ & $0,20^{* *}$ & 1,10 \\
\hline Beleza & 0,01 & 0,00 & 0,01 & $-0,17$ \\
\hline Conhecimento & $-0,15^{*}$ & 0,10 & $-0,03$ & 1,22 \\
\hline Justiça Social & $-0,19^{* *}$ & $0,29^{* * *}$ & $0,19^{* *}$ & $1,84^{*}$ \\
\hline Maturidade & $-0,28^{* * *}$ & $0,17^{* *}$ & $0,25^{* * *}$ & 1,45 \\
\hline SOCIAIS & $-0,14^{*}$ & $-0,04$ & 0,12 & $-1,40$ \\
\hline Interacionais & $0,16^{*}$ & 0,05 & $0,17^{*}$ & $-2,11^{* *}$ \\
\hline Afetividade & 0,09 & 0,06 & 0,13 & $-1,22$ \\
\hline Apoio Social & $-0,12$ & 0,07 & $0,20^{* *}$ & $-2,30^{* *}$ \\
\hline Convivência & $-0,00$ & $-0,04$ & $-0,01$ & 0,52 \\
\hline Honestidade & $-0,19^{* *}$ & 0,04 & $0,13^{*}$ & $-1,57^{*}$ \\
\hline Normativos & $-0,07$ & $-0,08$ & 0,03 & 0,87 \\
\hline Obediência & $-0,18^{* *}$ & 0,01 & 0,14 & $-2,27^{* *}$ \\
\hline Ordem Social & $-0,02$ & 0,04 & 0,06 & $-0,35$ \\
\hline Religiosidade & $-0,05$ & $-0,03$ & $-0,00$ & 0,52 \\
\hline Tradição & $-0,08$ & $-0,18^{* *}$ & $-0,07$ & $1,94^{*}$ \\
\hline
\end{tabular}

Nota: ${ }^{*} p \leq 0,05 ;{ }^{* *} p \leq 0,01 ;{ }^{* * *} p \leq 0,001$.

Como pode ser visto com relação às atitudes preconceituosas, foram observadas correlações significativas $(p \leq 0,05)$ desse construto com os valores humanos. De forma direta, as atitudes correlacionaram-se com os valores de Realização $(r=0,33)$, especificamente com o valor Poder $(r=0,27)$. Já de maneira inversa, observaram-se correlações, principalmente, com os valores Suprapessoais $(r=-0,27)$, especificamente com Maturidade $(r=-0,28)$, Justiça Social $(r=-0,19)$ e Conhecimento $(r=-0,15)$; e com os Interacionais $(r=-0,16)$, particularmente com Honestidade $(r=-0,19)$.

No que diz respeito à intenção em manter o contato social, observou-se que a intenção em manter contato social superficial correlacionou-se principalmente, direta e significativamente $(p \leq 0,05)$, com os valores Suprapessoais $(r=0,26)$, especificamente com Justiça Social $(r=0,29)$ e Maturidade $(r=0,17)$. Ademais, de forma negativa, as correlações observadas foram com os valores de Realização $(r=-0,23)$, especificamente com Poder $(r=-0,24)$ e Prestígio $(r=-0,10)$; bem como com o valor básico Tradição $(r=-0,18)$.

Por sua vez, a intenção em manter o contato social íntimo apresentou correlações diretas e significativas $(\phi \leq 0,05)$, principalmente, com os valores 
Suprapessoais $(r=-0,20)-$ particularmente com Maturidade $(r=0,25)$ e Justiça Social $(r=0,19)-\mathrm{e}$ Interacionais $(r=-0,17)$, especificamente com Apoio Social $(r=-0,20)$ e Honestidade $(r=-0,13)$. Já de forma indireta, as principais correlações foram com os valores de Realização $(r=-0,26)$, especificamente com Poder $(r=-0,22)$, Prestígio $(r=-0,19)$ e Exxito $(r=-0,16)$.

Para analisar as possíveis diferenças entre os coeficientes de correlação dos dois tipos de intenção em manter o contato social, foi efetuado um teste para comparação de índices de correlação de uma mesma amostra. Ao considerar os pares de correlação (o tipo superficial comparado com o tipo íntimo) que tiveram ao menos um coeficiente significativo, observaram-se diferenças $(\not \leq 0,05)$ entre alguns desses índices. Tais diferenças foram verificadas nos seguintes valores: nos Interacionais $(z=-2,11)$, especificamente nos valores
Apoio Social $(z=-2,30)$ e Honestidade $(z=-1,57)$; bem como nos valores básicos Estabilidade Pessoal $(z=$ 1,57), Justiça Social $(z=1,84)$ e Tradição $(z=1,94)$. Os valores humanos nos quais os contrastes $(z)$ apresentaram sinal positivo apresentaram índices de correlação significativamente maior no tipo superficial em comparação com o tipo íntimo, ocorrendo o inverso quando o sinal do contraste era negativo.

Com o intuito de verificar o poder preditivo dos valores sobre as atitudes preconceituosas, decidiu-se realizar uma análise de regressão. Neste sentido, optouse por introduzir as seis funções psicossociais dos valores como variáveis independentes e as atitudes foram tratadas como variável dependente. Para tal, foi adotado o método stepwise, tendo-se verificado ao final da análise um modelo explicativo das atitudes constituído por duas funções valorativas (ver Tabela 2).

Tabela 2 - Regressão múltipla para as atitudes preconceituosas

\begin{tabular}{lccccc}
\hline Variável Independente & $\mathrm{R}$ & $\mathrm{R}_{\text {ajustado }}$ & $\mathrm{F}$ & Betaz & $t$ \\
\hline Valores Suprapessoais & 0,30 & 0,09 & $\mathrm{~F}(1 ; 205)=20,4^{* * *}$ & $-0,36$ & $-5,33^{* * *}$ \\
Valores de Realização & 0,37 & 0,13 & $\mathrm{~F}(2 ; 204)=16,4^{* * *}$ & 0,23 & $3,36^{* *}$ \\
\hline
\end{tabular}

Nota: ${ }^{* * *} p<0,001$.

O modelo considera conjuntamente as funções valorativas Suprapessoal e de Realização [F (2/204) = $16,4 ; p<0,001]$, tendo ele explicado $13 \%$ da variância total ( $\mathrm{R}^{2}$ ajustado) das atitudes preconceituosas. Os valores Suprapessoais ( $\beta_{\text {Padronizado }}=-0,36$ ) atuam explicando negativamente essas atitudes, ao passo que os valores de Realização contribuem de forma direta ( $\beta_{\text {Padronizado }}=$ $0,23)$ na explicação das mesmas, sendo tais indicadores estatisticamente significativos $(t>1,96)$.
Finalmente, procurou-se também conhecer quanto as atitudes preconceituosas explicam a intenção em manter o contato social com negros. Para esse fim, tendo em vista que os dois tipos de contato social encontram-se relacionados entre si (Martínez \& Vera, 1994), foi calculada uma pontuação total para a intenção em manter contato, sendo o referido construto, nessa análise, tratado unifatorialmente. Do mesmo modo que antes, também foi utilizada uma análise de regressão adotando-se o método stepwise.

Tabela 3 - Regressão múltipla para a intenção em manter contato social

\begin{tabular}{lccccc}
\hline Variável Independente & $\mathrm{R}$ & $\mathrm{R}^{2}$ ajustado & $\mathrm{F}$ & Betaz & $t$ \\
\hline Atitudes Preconceituosas & 0,50 & 0,25 & $\mathrm{~F}(1 ; 213)=71,5^{* * *}$ & $-0,50$ & $-8,46^{* * *}$ \\
\hline
\end{tabular}

Nota: ${ }^{* * *} p<0,001$.

De acordo com a Tabela 3 acima, verificou-se que as atitudes preconceituosas $[\mathrm{F}(1 / 213)=71,5 ; p<$ $0,001]$ entraram no modelo de regressão explicando $25 \%$ da variância da intenção para manter o contato social, tratando-se de uma explicação estatisticamente significativa $(t>1,96)$ e de ordem inversa $\left(\beta_{\text {Padronizado }}=-0,50\right)$.

\section{Discussão}

O presente estudo buscou conhecer como os valores humanos relacionam-se com as atitudes preconceituosas e com a intenção em manter contato social, seja íntimo ou superficial, bem como avaliar o poder explicativo que os valores têm sobre as atitudes preconceituosas e como estas explicam a intenção em manter o contato social com negros. Os resultados encontrados alinham-se com estudos anteriores e endossam a relevância em considerar os valores e as atitudes na compreensão da intenção comportamental, particularmente na dinâmica do preconceito.

Os valores foram aqui analisados desde a hipótese da dependência, que parte do princípio de que valores específicos seriam responsáveis por promover ou inibir o preconceito. Boa parte dos resultados encontrados, como já comentado, são consonantes com a literatura (Gómez e Huici, 2001; Vera \& Martinez, 1994), principalmente no que se refere à relação inversa entre os valores Suprapessoais, equivalente ao universalismo na tipologia de Schwartz (1994), e às atitudes preconceituosas. Também foi encontrada uma correlação direta com valores de Realização, igualmente referenciada na literatura (Vera \& Martinez, 1994). 
Ao se fazer uma análise de tais correlações e tendo em consideração as características definidoras dos valores básicos (Gouveia, 1998), se poderia, de maneira geral, descrever uma pessoa preconceituosa como alguém que dá prioridade aos próprios benefícios e ao sentimento de ser importante e poderoso, além de buscar o mantenimento de situações e/ou relações desiguais que o favoreça. Por outro lado, aquelas pessoas com uma baixa magnitude de preconceito tenderiam a ser pessoas mais maduras, que teriam menos preocupações materiais e seriam menos limitadas a características descritivas ou traços específicos para iniciar uma relação ou promover benefícios. Os valores enfatizados por essas pessoas ressaltam a importância dos demais, não exclusivamente dos indivíduos que compõem o grupo de pertença.

No que tange às intenções em manter contato social com negros, tanto o superficial quanto o íntimo, apresentaram um padrão de correlações semelhantes, com ênfase nos valores Suprapessoais (positivamente) e de Realização (negativamente). Evidências anteriores (Sagiv \& Schwartz, 1995) sinalizam nesta mesma direção. Uma das diferenças no padrão de correlação entre os tipos de intenção em manter o contato é o fato de que valores como os Interacionais caracterizam mais particularmente a intenção de manter contato íntimo; ao passo que, os valores básicos como Justiça Social, Tradição e Estabilidade Pessoal foram os que assinalaram mais fortemente o tipo superficial de intenção.

Como se observou nos resultados do presente estudo, os valores humanos, sobretudo os Suprapessoais e os de Realização, funcionaram como bons explicadores das atitudes preconceituosas. Já no que tange à relação entre atitudes e condutas, aqui não foi utilizada nenhuma medida comportamental direta, mas uma de intenção de comportamento. Vale, pois, ressaltar que a intenção comportamental é aludida como o construto mais diretamente envolvido na determinação dos comportamentos (Fishbein \& Ajzen, 1975). Dessa forma, o que aqui se encontrou não deixa de ser consistente com o modelo acima referido, uma vez que os valores explicaram bem as atitudes preconceituosas, e estas se mostraram como excelentes preditoras da intenção em manter contato social com negros.

Para concluir, cabe observar que em estudos futuros, partindo das evidências aqui apresentadas, poderia ser interessante a testagem de um modelo teórico considerando os construtos aqui trabalhados. Finalmente, levando em conta os aspectos abordados neste estudo, cabe assinalar sua modesta contribuição no sentido de complementar a ampla discussão sobre a temática do preconceito, sobretudo na medida em que põe ênfase nos valores humanos como construto relevante para compreensão das manifestações preconceituosas. Tendo sido este o objetivo principal do presente estudo, pode-se considerá-lo atingido com êxito. Finalmente, ressalta-se a necessidade e relevância científica e social de estudos que abordem o preconceito e suas manifestações em diferentes contextos culturais, por ser esta mais uma das variáveis que influem neste fenômeno.

\section{Referências}

Allport, G. W. (1954). The nature of prejudice. Reading, Mass: Addison-Wesley Publishing.

Biernat, M., Vescio, T. K., Theno, S. A. \& Crandall, C. S. (1996). Values and prejudice: Toward understanding the impact of American values an outgroup attitudes. Em C. Seligman, J. M. Olson \& M. P. Sanna (Orgs.). The psychology of values: The Ontario Symposium, vol. 8 (pp. 153-189). Mahwah, NJ: Lawrence Erlbaum Associated.

Brown, R. (1995). Prejudice: Its social psycchology. Oxford: Blackwell.

Chaves, S. S. S. (2003). V alores como preditores do bem-estar subjetivo (Dissertação de Mestrado). João Pessoa, PB: Universidade Federal da Paraíba - Departamento de Psicologia.

Coelho, J. A. P. M., Gouveia, V. V., Milfont, T. L., Meira, M. \& Schultz, P. W. (2000). Valores humanos como explicação de atitudes ambientais. Anais do $V$ CCHLA - Conbecimento e Debate (p. 145). João Pessoa, PB.

Coelho Júnior, L. L. (2001). Uso potencial de drogas em estudantes do ensino médio: suas correlações com as prioridades axiológicas (Dissertação de Mestrado). João Pessoa, PB: Universidade Federal da Paraíba - Departamento de Psicologia.

Costa, D. M. F. (2001). Aspectos do preconceito étnico em relação ao negro: um estudo empírico no setor supermercadista de João Pessoa (Dissertação de Mestrado). João Pessoa, PB: Universidade Federal da Paraíba - Departamento de Psicologia.

Cover, J. D. (1995). The effects of social contact on prejudice. The Journal of Social Psychology, 135, 403.

Fishbein, M \& Ajzen, I. (1975). Belief, attitude, intention and behavior: An introduction to theory and research. Reading, MA: Addison-Wesley.

Formiga, N. S. (2002). Condutas anti-sociais e delitivas: uma explicação baseada nos valores bumanos (Dissertação de Mestrado). João Pessoa, PB: Universidade Federal da Paraíba - Departamento de Psicologia.

Gómez, A. \& Huici, C. (2001). Valores y reducción del prejuicio. Em M. Ros \& V. V. Gouveia (Orgs.). Psicología social de los valores bumanos: avances teóricos, metodológicos y aplicados. Madrid: Biblioteca Nueva.

Gouveia, V. V. (1998). La naturaleza de los valores descriptores del individualismo y del colectivismo: una comparación intra e 
intercultural (Tese de Doutorado). Madrid: Universidad Complutense de Madrid - Faculdade de Psicología.

Gouveia, V. V., Albuquerque, F. J. B., Clemente, M. \& Espinosa, P. (2002). Human values and social identities: A study in two collectivist cultures. International Journal of Psychology, 37(6), 333-342.

Gouveia, V. V., Souza Filho, M. L., Chaves, S. S. S., Rivera, G. A. \& Queiroga, F. (2003). Relação entre os valores humanos e a motivação interna e externa para responder sem preconceito [Resumo]. Anais do III Congresso Norte-Nordeste de Psicologia (pp. 341). João Pessoa, PB.

Homer, P. M. \& Kahle, L. R. (1988). A structural equation test of the value-attitude-behavior hierarchy. Journal of Personality and Social Pyschology, 54(4), 638-646.

Jones, J. M. (1973). Racismo e preconceito. São Paulo: Editora da Universidade de São Paulo.

Maia, L. M. (2000). Prioridades valorativas e desenvolvimento moral: consideracões acerca de uma teoria dos valores bumanos (Dissertação de Mestrado). João Pessoa, PB: Universidade Federal da Paraíba - Departamento de Psicologia.

Martinez, M. C. \& Vera, J. J. (1994). La estructura del prejuicio: realidad y simbolismo. Boletín de Psicología, 42, 21-38.

Maslow, A. H. (1954/1970). Motivation and personality. New York: Harper \& Row Publishers.

Milfont, T. (2001). Intenção em constituir familia: suas bases normativas e relacionais (Dissertação de Mestrado). João Pessoa, PB: Universidade Federal da Paraíba Departamento de Psicologia.

Navas, M. S. (1998). Nuevos instrumentos de medida para el nuevo racismo. Revista de Psicología de Social, 13, 233-239.

Pettigrew, T. F. \& Meertens, R. W. (1995). Subtle and blantant prejudice in Western Europe. European Journal of Social Psychology, 25, 57-75.

Plant, E. A. \& Devine, P. G. (1998). Internal and external motivation to respond without prejudice. Journal of Personality and Social Psychology, 75, 811-832.
Pozo B. C., Armas, L. G. C. \& Peres, A. R. (2000). Son los miembros del exogrupo étnico capaces de sentir igual que nosostros? La atribuición de emociones diferentes a exogrupos y endogrupos. Em D. Caballero, M. T. Méndez \& J. Pastor (Orgs.). La mirada psicosociológica (pp. 247-252). Madrid: Biblioteca Nueva.

Rodrígues-Bailón, R., Barranco, J. \& Casado, P. (2000). Tipos motivacionales de valores dominantes $y$ prejuicio hacia grupos minoritários. Em D. Caballero, M. T. Méndez \& J. Pastor (Orgs.). La mirada psicosociológica (pp. 273-279). Madri: Biblioteca Nueva.

Rokeach, M. (1973). The nature of buman values. New York: Free Press.

Sagiv, L. \& Schwartz, S. H. (1995). Value priorities and readiness for out-group social contact. Journal of Personality and Social Psychology, 69, 437-448.

Schwartz, S. H. (1994). Are there universal aspects in the structure and contents of human values? Journal of Social Issues, 50, 19-45.

Schwartz, S. H. \& Bilsky, W. (1987). Toward a universal psychological structure of human values. Journal of Personality and Social Psychology, 53, 550-562.

Stephan, W., Ybarra, O, Martínez, C., Schwarzwald, J. \& Tur-Kaspa, M. (1998). Prejudice toward immigrants to Spain and Israel: An integrated threat theory analysis. Journal of Cross-Cultural Psychology, 29, 559-576

Struch, N. \& Schwartz, S. H. (1989). Intergroup aggression: Its predictors and distinctness from in-group bias. Journal of Personality and Social Psychology, 56, 364-373.

Vera, J. J. \& Martínez, M. C. (1994). Preferencias de valores en relación con los prejuicios hacia exogrupos. Anales de Psicología, 10, 29-40.

Recebido em agosto de 2004

Reformulado em novembro de 2004 Aprovado em dezembro de 2004

Sobre aos autores:

Tatiana Cristina Vasconcelos é mestre em Psicologia Social pela Universidade Federal da Paraíba e professora do Instituto de Ensino Superior de Cajazeiras.

Valdiney V. Gouveia é doutor em Psicologia Social pela Universidade Complutense de Madrid e professor da PósGraduação em Psicologia Social da Universidade Federal da Paraíba.

Marcílio Lira de Souza Filho é psicólogo pela Universidade Federal da Paraíba.

Deliane Macedo Farias de Sousa é psicóloga pela Universidade Federal da Paraíba e Bolsista de Iniciação Científica - CNPq.

Girlene Ribeiro de Jesus é mestre em Psicologia pela Universidade de Brasília e colaboradora do Centro de Seleção e Promoção de Eventos - CESPE. 